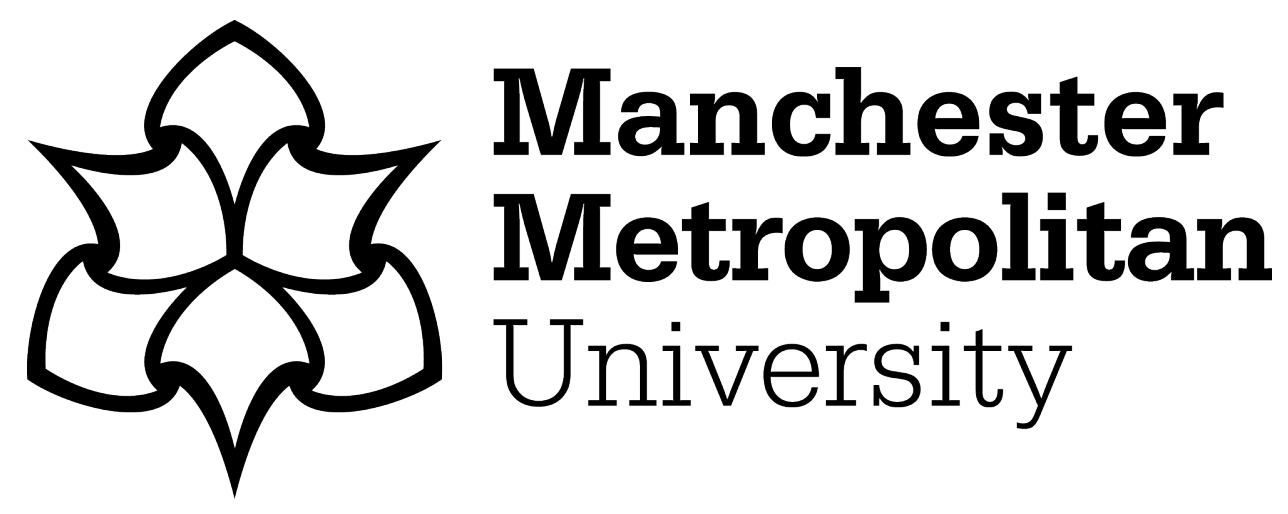

Rämä, P, Sirri, L and Goyet, L (2018) Event-related potentials associated with cognitive mechanisms underlying lexical-semantic processing in monolingual and bilingual 18-month-old children. Journal of Neurolinguistics, 47. pp. 123130. ISSN 0911-6044

Downloaded from: https://e-space.mmu.ac.uk/621991/

Version: Accepted Version

Publisher: Elsevier

DOI: https://doi.org/10.1016/j.jneuroling.2018.04.012

Usage rights: Creative Commons: Attribution-Noncommercial-No Derivative Works 4.0

Please cite the published version 


\title{
Event-related potentials associated with cognitive mechanisms underlying lexical-semantic processing in monolingual and bilingual 18-month-old children
}

\author{
Pia Rämäa,b,*, Louah Sirri ${ }^{\mathrm{a}}$, Louise Goyet ${ }^{\mathrm{c}}$ \\ ${ }^{a}$ Université Paris Descartes, Sorbonne Paris Cité, Paris, France \\ ${ }^{\mathrm{b}}$ CNRS, Laboratoire Psychologie de la Perception (UMR 8242), Paris, France \\ ${ }^{\mathrm{c}}$ Laboratoire Paragraphe (EA349), Université Paris 8 Vincennes, Saint-Denis, France
}

\section{A R T I C L E I N F O}

\section{Keywords:}

Semantic priming

Language-related ERPs

Bilinguals

Automatic activation

Controlled mechanisms

Language development

\begin{abstract}
A B S T R A C T
Prior to their second birthday, children are sensitive to the semantic relatedness between spoken words. Yet, it remains unclear whether simultaneous second language acquisition affects this sensitivity. Here, we investigated the influence of early acquisition of two languages on the eventrelated potentials (ERPs) associated with lexical-semantic processing of spoken words in 18month-old monolingual and bilingual children. Children were exposed to an auditory semantic priming task in French, while their ERPs were recorded. Word pairs were either semantically related (e.g., train-bike) or unrelated (e.g., chicken-bike), and they were presented at two stimulus onset asynchronies (SOA). The results revealed that only monolingual children exhibited a semantic priming effect at the short SOA while at the long SOA condition, both monolingual and bilingual children exhibited more pronounced ERPs in response to unrelated compared with related target words. This finding suggests that both language groups are sensitive to taxonomic relations between words but activation of sematic network might be less automatized or slower in bilingual children.
\end{abstract}

\section{Introduction}

Hearing or reading a word activates semantically related words in the lexical-semantic network, thus facilitating the processing of subsequent words. This effect is known as 'semantic priming'. Priming effects are typically studied in lexical-decision tasks, during which participants are presented with prime-target word pairs and their task is to decide whether the target is a word or a non-word. The reaction times are faster and more accurate when the target word is preceded by a related word than by an unrelated word (e.g., Meyer \& Schvaneveldt, 1971). Two distinct processes or strategies-automatic and controlled-have been suggested to contribute to the semantic priming effect. While the former is fast acting and occurs when the temporal window between the onsets of the two words (prime and target) is short (around $400 \mathrm{~ms}$; Quillian, 1962; Collins \& Loftus, 1975), the latter involves expectancy and postlexical matching, demands attention allocation, and occurs when the temporal window between the onsets of the two words (prime and target) is long (> $400 \mathrm{~ms}$; Posner \& Snyder, 1975; Becker, 1976; Neely, 1977, 1991; Shiffrin \& Schneider, 1977; Brown \& Hagoort, 1993). In addition to behavioural tasks, the lexical-semantic organization has been extensively investigated by measuring event-related potentials (ERPs) in response to target words in semantic priming tasks. It has been shown that the amplitudes of the N400 component are more negative in response to target words (e.g., table) preceded by unrelated (e.g., dog) than by related (e.g.,

\footnotetext{
* Corresponding author. Laboratoire Psychologie de la Perception (CNRS, UMR 8242), Université Paris Descartes, 45, rue des Saints-Pères, 75006, Paris, France. E-mail address: pia.rama@parisdescartes.fr (P. Rämä).
} 
chair) prime words (e.g., Kutas \& Hillyard, 1980; Federmeier \& Kutas, 1999; for a review, see; Kutas \& Federmeier, 2000), suggesting that the occurrence of the N400 is associated with processing of semantics in a context. Both automatic and controlled processes have been suggested to underlie also the N400 priming effect (e.g., Chwilla, Hagoort, \& Brown, 1998; Deacon, Hewitt, Yang, \& Nagata, 2000; Kiefer, 2002; Silva-Pereyra et al., 1999) but its magnitude is augmented at longer SOAs when controlled processes are engaged (e.g., Anderson \& Holcomb, 1995; Hill, Ott, \& Weisbrod, 2005).

There is accumulating evidence that towards their second birthday, children start to develop a lexical-semantic system based on different semantic relationships. Taxonomic (e.g., chicken - dog) or associative (e.g., cat - dog) relationships between words were previously shown to emerge by the age of 24-months (e.g., Arias-Trejo \& Plunkett, 2009; Arias-Trejo \& Plunkett, 2013; Rämä, Sirri, \& Serres, 2013; Styles \& Plunkett, 2009; Torkildsen, Syversen, Simonsen, Moen, \& Lindgren, 2007; Willits, Wojcik, Seidenberg, \& Saffran, 2013) but further studies have shown that these relationships between word meanings emerge even earlier, at 18-months of age (Delle Luche, Durrant, Floccia, \& Plunkett, 2014; Rämä et al., 2013; Sirri \& Rämä, 2015). In ERP studies, a semantic N400 priming effect for spoken words has been found in 18- and 24-month-olds (Rämä et al., 2013; Sirri \& Rämä, 2015) while a larger N400 amplitude for inconsistent than for consistent object-word pairs has been found already from 12 months of age (Friederici, 2006; Friedrich and Friederici, 2006; Friedrich \& Friederici, 2004, 2005a, 2005b, 2010). All these studies suggest that the neural generator mechanisms of N400 are mature early in development but some of the findings suggest that vocabulary skills contribute to the development of a taxonomically organized lexical-semantic system (e.g., Rämä et al., 2013; Torkildsen et al., 2006). There are also other ERP components that have been associated with lexical processing, such as the N2 (Friedrich \& Friederici, 2004; Mills, Coffey-Corina, \& Neville, 1997, 1993; Thierry, Vihman, \& Roberts, 2003; Torkildsen et al., 2007) and late negativity (Friedrich \& Friederici, 2004; Torkildsen et al., 2007). The N2 component has been associated with word familiarity (Mills, Coffey-Corina, \& Neville, 1993, 1997), attention to lexical information (Thierry et al., 2003), and lexical expectancy or facilitation (Friedrich \& Friederici, 2004; Torkildsen et al., 2007) while the late negativity, continuing beyond the N400 window, has been suggested to indicate slower semantic processing in younger children (Friedrich \& Friederici, 2004; Torkildsen et al., 2007).

The aim of the current study was twofold: First, to investigate the occurrence and the distribution of ERPs in response to semantic relatedness in bilingual children to ascertain whether simultaneous dual language experience affects lexical-semantic processing, and second, to explore whether the magnitude or/and the distribution of ERPs are modulated by the SOA length to further investigate the cognitive mechanisms underlying semantic priming. In bilingual children, linguistic experience is divided between their two languages, which results in less experience with words in each language compared with monolingual children, which might in turn affects the development of their lexical-semantic system. Despite the fact that bilingual children need to construct in parallel two different phonological-lexical systems and learn two words for each object or concept, they achieve their language milestones in each of their languages at the same age (e.g., Oller, Eilers, Urbano, \& Cobo-Lewis, 1997; Pearson, Fernandez, \& Oller, 1993; Petitto et al., 2001). There is, however, evidence that bilinguals tend to have a smaller vocabulary in each of their languages even if the total vocabulary has been reported to be comparable to that of monolinguals (e.g., Bialystok, 2009; Hoff, Core, Place, Rumiche, Senor, \& Parra, 2012; Poulin-Dubois, Bialystok, Blaye, Polonia, \& Yott, 2013). Additionally, it has been shown that the speed of familiar word processing in two and half years old bilingual children was linked to the vocabulary knowledge in a given language but unrelated to the processing efficiency of the other language (Marchman, Fernald, \& Hurtado, 2010). A few ERP studies investigated the neural correlates of word processing in bilingual children. Conboy and Mills (2006) explored the ERP components in response to known and unknown words in each of the 19- to 22-month-old bilinguals' languages. The results showed that the word familiarity effect (as reflected by more pronounced N200 and N400 amplitudes to known than to unknown words) was larger and occurred earlier for the dominant (the language to which children were mostly exposed in total time; hereafter: DL) than for the non-dominant (the language to which children were less exposed; hereafter: NDL) language. In addition, the distribution of language-related ERPs was shown to vary across the DL and the NDL in two-to four-year-old toddlers: The posteriorly distributed N400 component was observed for the DL only whereas processing of the NDL activated frontally distributed resources over the left scalp positions (Sirri \& Rämä, 2017). Two other studies investigating lexical-semantic processing of the DL in 30-month-old bilingual toddlers showed that in a wordpicture priming task, bilingual toddlers exhibited a similar N400 effect in their DL as their monolingual peers (Kuipers \& Thierry, 2013, 2015). Altogether, these earlier ERP findings suggest that while lexical-semantic processing differs across the two languages of bilinguals, lexical-semantic processing in a picture-word context in the DL remains similar to that of their monolingual peers, at least at the ages of $2-4$ years.

Our aim was to investigate whether bilingual children process lexical-semantic information similarly to their monolingual peers in a spoken word context already at earlier age and whether the SOA length modulates the ERPs to further understand the cognitive mechanisms underlying semantic priming in bilingual children. For 18-month-old monolingual children, our earlier results showed that the amplitudes of the N2 and LPN were modulated by both semantic relatedness and SOA length, whereas the N400 component was modulated only by semantic relatedness (Sirri \& Rämä, 2015). The amplitudes of the frontally distributed N2 were larger for unrelated than for related words at the long SOA, while the semantic priming effect for posteriorly distributed LPN was larger over the right hemisphere at the short SOA and more pronounced over the left hemisphere at the long SOA. Even though there is no developmental evidence on the relation between the SOA length and associated cognitive processes, our findings suggested that both automatic and controlled processes might contribute to priming effects already in the developing brain. In the present work, the experimental design and its procedure respected that of Sirri and Rämä (2015): Children of 18-months were presented with word pairs (with two variable SOA lengths) that we were either taxonomically related or unrelated. We chose relatively long SOAs in both experimental conditions since in the auditory modality, simultaneous or overlapping word presentation (with SOAs of 0 ms or $200 \mathrm{~ms}$ ) has been shown to attenuate the N400 priming effect (Anderson \& Holcomb, 1995). Additionally, 18-month old children are slower at identifying familiar spoken words than older children (Fernald, Pinto, Swingley, Weinbergy, \& McRoberts, 1998). Based on 
Table 1

Parental estimation (in \%) of the amount of exposure to bilinguals' two languages.

\begin{tabular}{lll}
\hline & Language exposure in $\%$ & \\
\hline S1 & French: 20 & Arabic: 80 \\
S2 & French: 40 & Finnish: 60 \\
S3 & French: 40 & Arabic: 60 \\
S4 & French: 40 & Hebrew: 60 \\
S5 & French: 50 & English: 50 \\
S6 & French: 50 & Arabic: 50 \\
S7 & French: 50 & Russian: 50 \\
S8 & French: 60 & Spanish: 40 \\
S9 & French: 60 & Italian/Kabyle: 40 \\
S10 & French: 60 & Spanish: 40 \\
S11 & French: 60 & Spanish: 40 \\
S12 & French: 60 & English/Italian: 40 \\
S13 & French: 75 & English: 35 \\
S14 & French: 70 & Italian: 30 \\
S15 & French: 70 & Russian: 30 \\
S16 & French: 70 & Finnish: 30 \\
S17 & French: 70 & Arabic: 30 \\
S18 & French: 70 & German: 30 \\
S19 & French: 80 & Russian: 20 \\
S20 & French: 80 & Arabic: 20 \\
\hline
\end{tabular}

previous findings (e.g., Petitto et al., 2001; Kuipers \& Thierry, 2013, 2015), we expected that bilingual children exhibit similar semantic priming effects than monolingual children already at the age of 18 months. However, vocabulary skills do not develop similarly in monolingual and bilingual children, and accordingly cognitive strategies or processing efficiency during word processing might differ, and thus, the effects of SOA on word processing might differ in our two language groups.

\section{Experimental procedure}

\subsection{Participants}

The ERP data from our previous study with monolingual children (Sirri \& Rämä, 2015) were included in the statistical analyses. Twenty 18-month-old (11 girls and 9 boys; range: 17 months and 4 days to 18 months and 25 days; mean 18 months and 8 days) monolingual and twenty 18-month-old (11 girls and 9 boys; range: 17 months and 9 days to 19 months and 19 days; mean 18 months and 28 days) bilingual children participated in the study. Children were recruited from a database of parents who voluntarily participated in previous studies in child development in our laboratory and came from the Paris area. All children were born full-term and none of them suffered from hearing or language impairment. The parents were informed about the purpose of the study and gave informed consent before participating. Children were raised in a family where one parent spoke French and the other parent another language (e.g., English, Russian, Arabic, Finnish). Parents filled the language background questionnaire and estimated the amount of their child's total exposure to each language. Of the twenty participants, thirteen children were mostly exposed to French (65\%-80\% of exposure time). Three children were equally exposed to both languages. Four children were more exposed to the other language (60\%-80\% of exposure time) than to French, and two were exposed to three languages. The mean exposure time of all children was $58 \%$ for French and $42 \%$ for another language (see, Table 1). An additional 11 children were tested but their data were rejected due to not being able to complete the experiment $(n=5)$ or insufficient number of trials (fewer than 10 trials) in one of the experimental conditions $(n=6)$. The French translation of the MacArthur Communicative Development Inventory for Words and Sentences (CDI; Fenson, Dale, Reznick, Thal, Bates, \& Hartung, 1993) was used to measure comprehensive and productive vocabulary size in French. The parents were asked to fill the inventory at home within the following two weeks. The parent who spoke French to the child was instructed to fill the inventory. The inventory was returned for 12 of the twenty children in our final sample. The study was conducted in conformity with the declaration of Helsinki and approved by the Ethics Committee of the University of Paris Descartes.

\subsection{Stimuli}

The stimuli were one-, two-, or three-syllable French nouns from eight different categories (animals, clothes, body parts, food, furniture, transportation, household items and nature). The words were presented in four different native female voices to prevent children from relying on acoustic information during the priming task. One hundred forty-four basic level words were chosen and arranged into 48 related and 48 unrelated prime-target word pairs. Each target word was presented four times during the experiment (twice in each SOA condition). Related words were taxonomically, but not associatively related (e.g., elephant-bear) and unrelated words were not semantically or associatively related (e.g., plane-bear). The mean number of syllables was 2 for related (SD $=1.78$ ), unrelated $(S D=1.68)$ and prime $(S D=1.68)$ words. The mean number of phonemes was $4(S D=4)$ for each word type. The mean durations were $649 \mathrm{~ms}, 663 \mathrm{~ms}$ and $669 \mathrm{~ms}$ for related, unrelated and target words, respectively. Paired sample t-tests did not yield 
significant differences between primes and targets for any of these three variables (all ps $>.05$ ). The recordings were edited with Cool Edit 2000 (Syntrillium Software Corp., Phoenix, AZ) and normalized at $22 \mathrm{kHz}$ sampling rate with Praat (5.3.02).

\subsection{Procedure}

Children were seated either by themselves on a small chair next to their parents or on their parents' laps at $140 \mathrm{~cm}$ from two loudspeakers from which sounds were delivered. Parents were instructed not to communicate verbally with their children during the experiment. Children had in front of them a small table with toys and crayons and were allowed to play or draw. No visual stimuli were presented during the experiment. As in our earlier study in monolingual 18-month-old children (Sirri \& Rämä, 2015) two stimulus onset asynchronies (SOA) were used, a short SOA of $1000 \mathrm{~ms}$ and a long SOA of $1600 \mathrm{~ms}$. Each target word was presented twice, once preceded by a related and once preceded by an unrelated prime, and each trial was repeated in both SOA conditions. Presentation order of trials was randomized. The intertrial interval (ITI) was $2200 \mathrm{msec}$ The whole experiment lasted about $12 \mathrm{~min}$.

\subsection{Event-related potential recording and analyses}

The electroencephalogram (EEG) was continuously recorded from 62 electrodes using a Geodesic Sensor Net (GSN, NetStation EGIS V2.0), filtered (band-pass $=0.1-100 \mathrm{~Hz}$ ) and digitized (sampling rate $=250 \mathrm{~Hz}$ ). During the recordings, the ERP electrodes were referenced to the vertex $(\mathrm{Cz})$. Impedances were kept below $50 \mathrm{k} \Omega$. Offline, the EEG was filtered $(0.3-30 \mathrm{~Hz})$ and segments of $800 \mathrm{~ms}$ from the word onset were averaged according to a 200-ms prestimulus baseline. Automated artifact rejection was conducted. The ocular artifact removal (OAR) algorithm was used to detect and remove eye blinks and eye movements (Gratton, Coles, \& Donchin, 1983). Trials including artifacts exceeding $\pm 160 \mu \mathrm{V}$ were rejected. Bad channels were replaced using spherical spline interpolation with the remaining channels. Segments with more than 20 bad channels were rejected. Epochs were averaged separately for each subject, target word type (related and unrelated), and SOA condition (short and long). The averaged segments were rereferenced to the average of left and right mastoids and, as a last step, baseline corrected. Epochs were grand-averaged across all participants for the target word type and SOA condition. A minimum of 10 artifact-free trials per word type and SOA condition were included in further analyses. The mean number of accepted trials was $17(35 \%)$ for related $(S D=5)$ and $18(37 \%)$ for unrelated $(S D=7)$ targets, at the short SOA, and $18(37 \%)$ for related $(S D=5)$ and $19(39 \%)$ for unrelated $(S D=7)$ targets at the long SOA. There were no significant differences in the number of trials between experimental conditions (all ps $>.05$ ). In monolinguals, the mean number of accepted trials was $16(33 \%)$ for related $(S D=5)$ and $17(35 \%)$ for unrelated $(S D=4)$ targets, at the short $S O A$, and $16(33 \%)$ for related $(S D=5)$ and $16(33 \%)$ for unrelated $(S D=5)$ targets at the long SOA. There were no significant differences in the number of trials between experimental conditions (all ps $>.05$ ).

\subsection{Data analyses}

The mean amplitudes of ERPs were calculated during the time windows of 150-350 ms (N2), 300-500 ms (N400), and 500-800 ms (LPN). A repeated-measures analysis of variance (ANOVA) included trial type (related versus unrelated target word), SOA (short versus long), and hemisphere (left versus right) as within-subject factors, and language group (monolinguals versus bilinguals) as a between-subject factor. The mean amplitudes of each component were calculated separately for each electrode in each time interval. The mean amplitudes of the N2 extracted from the eight frontal electrodes (for each hemisphere) were averaged. The mean amplitudes of the N400 and LPN extracted from the ten central-parietal electrodes (for each hemisphere) were averaged, resulting altogether in 36 channels in four regions of interest. The 36 channels with their approximate equivalents according to the 10-10 international system of electrodes sites are as follow: 14 (AF7), 12 (AF3), 19 (F9), 15 (F7), 13 (F3), 8 (F1), 16 (FC5), and 9 (FC1) in left frontal, 1 (AF8), 2 (AF4), 60 (F10), 61 (F8), 62 (F4), 3 (F2), 57 (FC6), and 58 (FC2) in right frontal, 24 (T7), 25 (CP5), 22 (CP3), 18 (CP1), 27 (P7), 28 (P3), 29 (P1), 31 (P9), 32 (PO7), and 33 (PO3) in left central-posterior, 52 (T8), 50 (CP6), 47 (CP4), 43 (CP2), 49 (P8), 46 (P4), 42 (P2), 48 (P10), 45 (PO8), and 41 (PO4) in right central-posterior. The statistical analyses were conducted with SPSS (IBM SPP statistics, version 20) and the Greenhouse-Geisser correction was applied for non-sphericity when appropriate.

\section{Results}

\subsection{Vocabulary skills}

The vocabulary inventory (for French words) of bilingual children was returned for 12 of the twenty children. The mean number of comprehended and produced words was 272 and 38, respectively. The vocabulary inventory of monolingual children was returned for 13 of the twenty children. The mean number of comprehended and produced words was 229 and 23, respectively. The difference in the number of comprehended $(\mathrm{t}(23)=0.649, \mathrm{p}=0.529)$ and produced $(\mathrm{t}(23)=0.895, \mathrm{p}=0.380)$ words between the Language groups was not significant.

\subsection{ERP results}

The ERP data of monolinguals (Sirri \& Rämä, 2015) were included in the statistical analyses to answer the question whether Language Group interacted with the main effects of trial type, SOA and/or hemisphere. Here, however, we detail only the interactions 


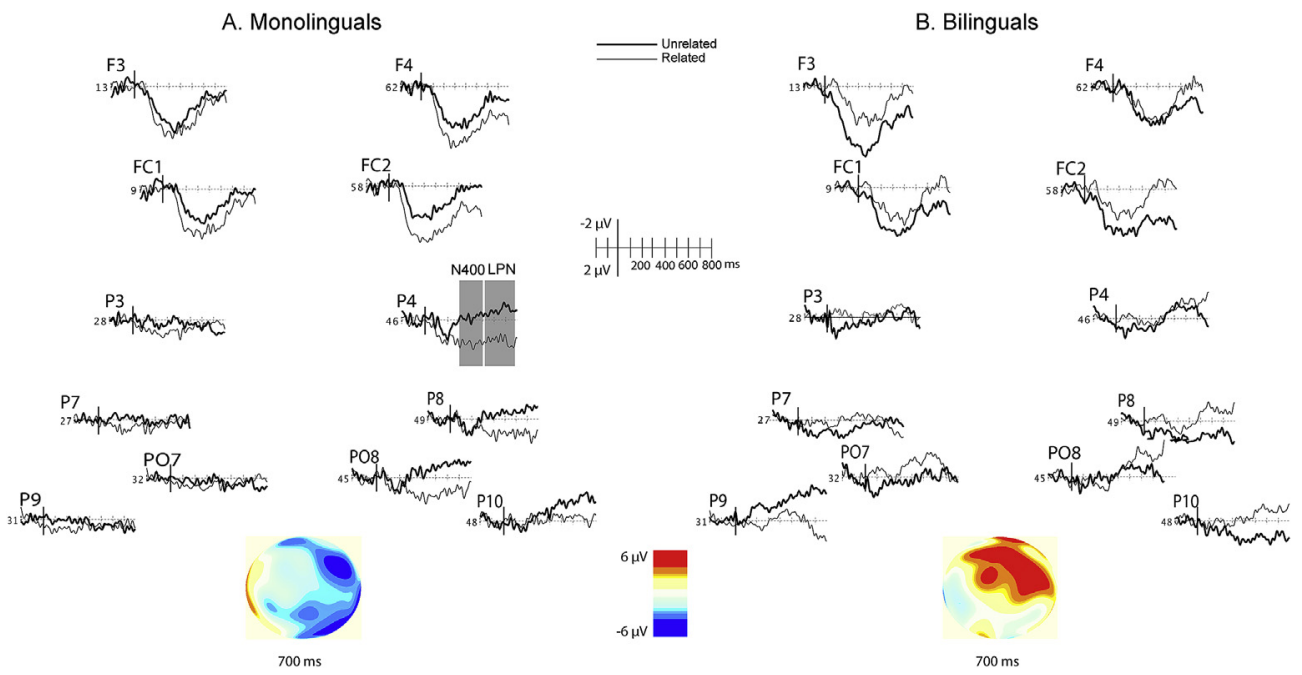

Fig. 1. Grand-averaged waveforms for unrelated (thick lines) and related (thin lines) target words over the frontal and parietal recording sites at the short SOA for the monolingual (A) and the bilingual (B) participants. The vertical lines illustrate the target word onset. The grey boxes indicate the N400 and LPN components at the right recording site (P4).

between Language Groups, and the main effects in the bilingual group.

\subsubsection{N2 component}

Over the frontal recording sites, there was a significant interaction between trial type and Language Group on the amplitudes of the $\mathrm{N} 2(\mathrm{~F}(1,38)=5.99 ; p=0.019)$. As reported earlier, the amplitudes of the $\mathrm{N} 2$ were more negative for unrelated than for related target words in monolinguals (Sirri \& Rämä, 2015), whereas in bilinguals, there was no main effect of trial type (related: $4.37 \mu \mathrm{V}$, $\mathrm{SD}=4.74$; unrelated $5.82 \mu \mathrm{V}, \mathrm{SD}=4.48)$ on the amplitudes of the $\mathrm{N} 2(\mathrm{~F}(1,19)=1.15 ; p=0.297)$. In addition, in monolinguals, the amplitudes of the N2 were more negative for unrelated words only at the long SOA (Sirri \& Rämä, 2015). In bilinguals, trial effects were not found either at the short $(\mathrm{t}(19)=0.21, \mathrm{p}=0.835)$ or the long $(\mathrm{t}(19)=-1.67, \mathrm{p}=0.112)$ SOA (Figs. 1 and 2). A significant trial effect was not found even when only bilingual participants with balanced or dominant exposure to French (n $=16$ ) were included in the analysis $(\mathrm{F}(1,15)=1.25 ; p=0.282)$.

\subsubsection{N400 and LPN components}

Over the central-posterior recording sites, there were no main effects or interactions with the Language Group on the amplitudes

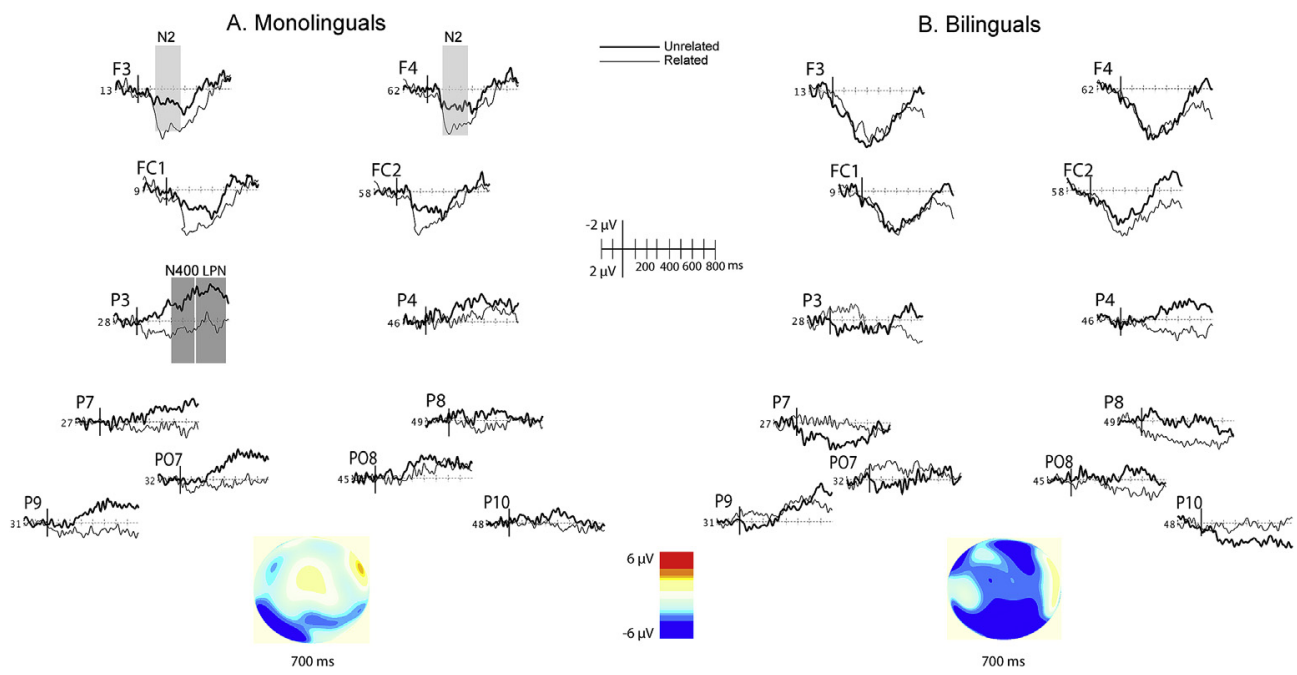

Fig. 2. Grand-averaged waveforms for unrelated (thick lines) and related (thin lines) target words over the frontal and parietal recording sites at the long SOA for the monolingual (A) and the bilingual (B) participants. The vertical lines illustrate the target word onset. The light grey boxes indicate the N2 component at the frontal recording sites (F3 and F4). The darker grey boxes indicate the N400 and LPN components at the left recording site (P3). 
of the N400 $(\mathrm{F}(1,38)=1.49 ; p=0.230)$. In our monolingual study, the main effect of trial type on the amplitudes of the N400 was close to significance ( $\mathrm{p}=0.051$ ) (Sirri \& Rämä, 2015) while in the current study, in the bilingual group only, the main effect of trial type was not significant $(\mathrm{F}(1,19)=0.084, \mathrm{p}=0.775)$.

A significant interaction between trial type, SOA, hemisphere and Language Group was found on the amplitudes of LPN (F $(1,38)=4.75 ; p=0.035)$. As reported earlier, a significant interaction between trial type, SOA, and hemisphere was found on the amplitudes of LPN in monolinguals (Sirri \& Rämä, 2015). The priming effect (unrelated minus related) was larger over the right than the left recording sites at the short SOA, whereas at the long SOA, the priming effect tended to be larger over the left than the right recording sites in monolingual children. In bilinguals, however, the interaction between trial type, SOA, and hemisphere ( $\mathrm{F}(1$, $19)=0.788, \mathrm{p}=0.386$ ) was not significant on the amplitudes of LPN (Figs. 1 and 2). There were also no main effects of trial type or SOA on the amplitudes of LPN in bilinguals. Moreoever, the main effects or interactions were not significant even when only bilingual participants with balanced or dominant exposure to French $(n=16)$ were included in the analysis.

To sum up, our results showed that there were no significant main effects of trial type, SOA, or their interactions on the amplitudes of the N2, N400, or LPN in the bilingual group when the same time windows and electrode sites were included in the statistical analyses as in our monolingual participants (see, Sirri \& Rämä, 2015). However, as illustrated in the topographical maps, the distribution of the N400 and the LPN varied across the Language Groups (see, Figs. 1 and 2). For the monolingual group, these two components were found dominantly over the left and the right recording sites, while for the bilingual group, the modulation of the N400 and LPN was observed more medially and posteriorly located central-parietal sites (Fig. 2). Thus, in the follow-up analysis, the amplitudes were extracted from fourteen medially and posteriorly located central-parietal sites (18 (CP1), 30 (CPz), 43 (CP2), 28 (P3), 29 (P1), 34 (Pz), 42 (P2), 46 (P4), 33 (PO3), 38 (POz), 41 (PO4), $37(\mathrm{O} 1), 40(\mathrm{O} 2)$, and $39(\mathrm{Oz})$ to test whether trial effects were significant over these recording sites. Language Group was included as a between-subject variable. The results showed that there were significant interactions between trial type and SOA for the amplitudes of the $\mathrm{N} 400(\mathrm{~F}(1,38)=4.57, p=0.039)$ and the LPN (F $(1,38)=5.25, p=0.028)$. The interaction between trial type, SOA, and the Language Group was not significant. The amplitudes of both components were more negative for unrelated than for related target words (the mean amplitudes of for related and unrelated words were $1.93 \mu \mathrm{V}$ (SD 5.24) and $-1.49 \mu \mathrm{V}$ (SD 6.89) for the N400 and 1.58 $\mu \mathrm{V}$ (SD 6.96) and $-2.33 \mu \mathrm{V}$ (SD 7.70) for the LPN, respectively) at the long SOA $(\mathrm{N} 400: \mathrm{t}(39)=2.54, \mathrm{p}=0.015$; $\mathrm{LPN}$ : $\mathrm{t}(39)=2.64, \mathrm{p}=0.012$, Fig. 3 ) but not at the short SOA (the mean amplitudes of for related and unrelated words were $-0.11 \mu \mathrm{V}$ (SD 7.12) and 1.30 $\mu \mathrm{V}$ (SD 7.26) for the N400 and -1.95 $\mu \mathrm{V}(6.85)$ and $-0.19 \mu \mathrm{V}$ (SD 7.56) for the $\mathrm{LPN}$, respectively) (N400: $\mathrm{t}(39)=-0.875, \mathrm{p}=0.387$; $\mathrm{LPN}$ : $\mathrm{t}(39)=-1.03, \mathrm{p}=0.310)$. In the follow-up test, we included only the bilingual participants to ascertain that our monolingual participants were not responsible for the significant trial effect at the long SOA. The interactions between trial type and SOA in bilinguals were marginal both for the N400 (F $(1,19)=3.09, \mathrm{p}=0.095)$ and the $\operatorname{LPN}(\mathrm{F}(1,19)=3.92, \mathrm{p}=0.062)$. However, $t$-test results indicated that the amplitudes were significantly more negative for unrelated than for related words (N400: $t(19)=2.50, p=0.022 ; \mathrm{LPN}$ : $\mathrm{t}(19)=2.36$, $\mathrm{p}=0.029)$ at the long SOA only (Fig. 3). These results indicate that the bilinguals exhibited a semantic priming effect (as measured by the N400 and LPN) at the long SOA. The effect was observed over the medially located posterior electrode sites.

\section{Discussion}

The current study aimed to investigate, first, whether bilingual infants at the age of 18 months exhibit sensitivity to semantic (taxonomic) relatedness between words similarly to their monolingual peers (Delle Luche et al., 2014; Rämä et al., 2013; Sirri \& Rämä, 2015), and second, whether the SOA between the prime and the target words modulates the magnitudes of their ERPs. The results showed that the amplitudes of the N400 and LPN were more pronounced for unrelated than for related target words in

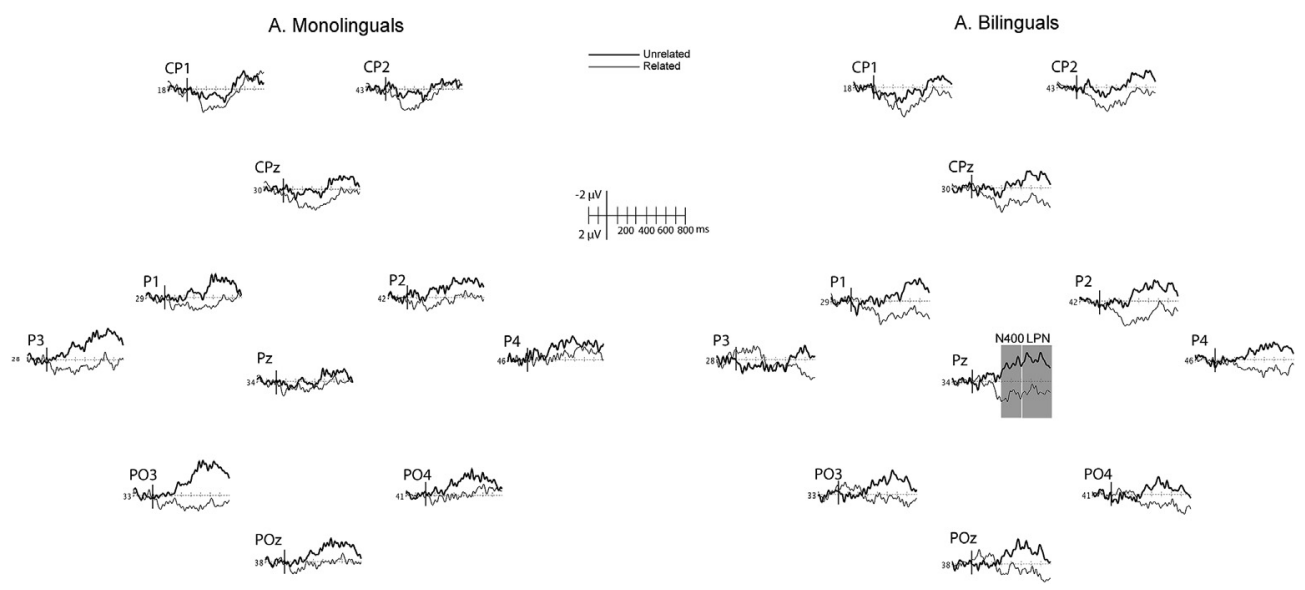

Fig. 3. Grand-averaged waveforms for unrelated (thick lines) and related (thin lines) target words over the midline recording sites at the long SOA for the monolingual (A) and the bilingual (B) participants. The vertical lines illustrate the target word onset. The grey boxes indicate the N400 and LPN components at the midline recording site (Pz). 
bilingual children, confirming that by 18 months, also bilingual children are sensitive to taxonomic relations between words. This suggests that exposure to two languages does not delay the development of the lexical-semantic organization. Several differences were, however, observed in the occurrence and the distribution of the ERPs between the monolingual and bilingual language groups. First, in the bilingual children, the priming effects on the N400 and LPN components were found at the long SOA only, whereas in the monolinguals, the LPN was modulated by trial type at both, short and long, SOAs (see, Sirri \& Rämä, 2015). Second, the ERPs were differently distributed over the scalp positions in the monolinguals and the bilinguals. In the monolinguals, the N400 and LPN effects were found over the left- and right lateral locations over the central-parietal recording sites while for bilinguals, the same effects were found over the medial posterior locations. Finally, in contrast to the monolingual children, the frontally distributed N2 component was not modulated by semantic relatedness for bilingual children. All these findings suggest that bilingual children are sensitive to the semantic relations between words at the age of 18 months, but their cognitive mechanisms underlying lexical-semantic processing might differ from those of monolingual children.

In adult studies, the N400 effect was shown to be sensitive to both automatic and controlled processing strategies but its magnitude is augmented at longer SOAs when controlled processes are more likely to be engaged (Anderson \& Holcomb, 1995; Hill et al., 2005). Our results showed that the bilingual children presented the N400 effect only at the long SOA while our earlier study with monolinguals showed that the priming effects were found for both long and short SOA conditions (Sirri \& Rämä, 2015). There are several possibilities to explain our findings: First, it suggests that the spreading of activation in the semantic network occurs less automatically in bilinguals than monolinguals, and at the short SOA, bilingual children do not activate semantic network as efficiently as monolingual children do. It has been earlier proposed that for bilingual children the semantic word representations in the DL are better established than those in the NDL (Singh, 2014), and also, that different neural resources underpin lexical-semantic processing in the DL and NDL (Sirri \& Rämä, 2017). Most of the children (16 out of 20 participants) in our study were equally or more exposed to French language, and the spoken words were presented in French. Thus, French could be considered as their dominant language. Four participants were more exposed to another language, but excluding their data from the analyses, did not change the results. This suggests that the lexical-semantic processing is less efficient for bilingual than for monolingual children, even in their dominant language.

Second explanation is that the bilingual children might have needed more time to activate lexical-semantic representations, and our (short) SOA condition was not sufficiently long. This alternative explanation would indicate that the lexical-semantic representations might be similar in the monolinguals and bilinguals but the speed of word processing is reduced in the bilinguals. It should be noted, however, that the mechanisms are not necessary the same in adults and in children since in a typical study conducted with adults, both short and long SOAs are much shorter than in our study with children. Thus, we cannot rule out the possibility that controlled processes were already engaged at our short SOA condition, and instead of manipulating automatic and controlled processes, we manipulated working memory load in our two SOA conditions. Nonetheless, altogether, our results suggest that cognitive mechanisms underlying word processing in bilinguals might be different from monolinguals even when bilinguals are processing their dominant language.

Additionally, even though both language groups exhibited priming effects (at long SOA), the distributions of the components were different. The N400 and LPN components were medially distributed over the posterior recording sites in the bilingual children while in the monolingual children we found the LPN effects over the right and the left hemispheres. In earlier studies in monolingual children, the N400 effect has been found to be equally large over the left and the right hemispheres (e.g., Friedrich \& Friederici, 2004), more pronounced over the right than the left hemisphere (Rämä et al., 2013) or temporally more extended over the left hemisphere (Friedrich \& Friederici, 2004; Torkildsen et al., 2006). However, in children with higher vocabulary skills, the N400 effect has been found over the right hemisphere (Friedrich \& Friederici, 2004, 2010; Rämä et al., 2013). In our sample, monolingual and bilingual children had similar vocabulary skills but still the distribution was slightly different in two language groups. Whether these distributional differences were due to less established lexical representations in bilingual children needs to be verified in studies testing both dominant and non-dominant bilinguals.

To conclude, our results suggest that, similarly to monolingual children, words are organized by their taxonomic relatedness in the lexicon of an 18-month-old bilingual child. The lack of semantic priming effect at the short SOA indicates that the children who are acquiring two languages, automatic processing is less efficient than in monolingual children, or they might need an additional time to process semantic relatedness. Our results suggest that even though the ERPs were sensitive to semantic manipulations in the both language groups, the cognitive processes underlying work processing might differ depending on language experience.

\section{Acknowledgement}

We thank all families for participating and contributing to this research. This work was funded by Sorbonne Paris Cité Grant.

\section{References}

Anderson, J. E., \& Holcomb, P. J. (1995). Auditory and visual semantic priming using different stimulus onset asynchronies: An event-related brain potential study. Psychophysiology, 32, 177-190.

Arias-Trejo, N., \& Plunkett, K. (2009). Lexical-semantic priming effects during infancy. Philosophical Transactions of the Royal Society B: Biological Sciences, 364(1536), 3633-3647.

Arias-Trejo, N., \& Plunkett, K. (2013). What's in a link: Associative and taxonomic priming effects in the infant lexicon. Cognition, $128(2), 214-227$. Becker, C. A. (1976). Allocation of attention during visual word recognition. Journal of Experimental Psychology: Human Perception and Performance, 2, 556-566. Bialystok, E. (2009). Bilingualism: The good, the bad, and the indifferent. Bilingualism: Language and Cognition, 12(01), 3-11. 
Brown, C. M., \& Hagoort, P. (1993). The processing nature of the N400: Evidence from masked priming. Journal of Cognitive Neuroscience, 5(1), 34-44.

Chwilla, D. J., Hagoort, P., \& Brown, C. M. (1998). The mechanism underlying backward priming in a lexical decision task: Spreading activation versus semantic matching. The Quarterly Journal of Experimental Psychology: Section A, 51(3), 531-560.

Collins, A. M., \& Loftus, E. F. (1975). A spreading-activation theory of semantic processing. Psychological Review, 82, $407-428$.

Conboy, B. T., \& Mills, D. (2006). Two languages, one developing brain: Event-related potentials to words in bilingual toddlers. Developmental Science, 9(1), 1-12.

Deacon, D., Hewitt, S., Yang, C. M., \& Nagata, M. (2000). Event-related potential indices of semantic priming using masked and unmasked words: Evidence that the N400 does not reflect a post-lexical process. Cognitive Brain Research, 9(2), 137-146.

Delle Luche, C., Durrant, S., Floccia, C., \& Plunkett, K. (2014). Implicit meaning in 18-month-old toddlers. Developmental Science, 1-8.

Federmeier, K. D., \& Kutas, M. (1999). A rose by any other name: Long-term memory structure and sentence processing. Journal of Memory and Language, 41, 469-495.

Fenson, L., Dale, P., Reznick, S., Thal, D., Bates, E., Hartung, J., et al. (1993). MacArthur communicative development Inventories: User's guide and technical manual. San Diego, CA: Singular Publishing Group.

Fernald, A., Pinto, J. P., Swingley, D., Weinbergy, A., \& McRoberts, G. W. (1998). Rapid gains in speed of verbal processing by infants in the 2nd year. Psychological Science, 9, 228-231.

Friederici, A. D. (2006). The neural basis of language development and its impairment. Neuron, 52(6), 941-952.

Friedrich, M., \& Friederici, A. D. (2004). N400-like semantic incongruity effect in 19-month-olds: Processing known words in picture contexts. Journal of Cognitive Neuroscience, 16, 1465-1477.

Friedrich, M., \& Friederici, A. D. (2005a). Lexical priming and semantic integration reflected in the event-related potential of 14-month-olds. NeuroReport, 16(6), 653-656.

Friedrich, M., \& Friederici, A. D. (2005b). Phonotactic knowledge and lexical-semantic processing in one-year-olds: Brain responses to words and nonsense words in picture contexts. Journal of Cognitive Neuroscience, 17, 1785-1802.

Friedrich, M., \& Friederici, A. D. (2006). Early N400 development and later language acquisition. Psychophysiology, 43, 1-12.

Friedrich, M., \& Friederici, A. D. (2010). Maturing brain mechanisms and developing behavioral language skills. Brain and Language, 114 , 66-71.

Gratton, G., Coles, M. G. H., \& Donchin, E. (1983). A new method for off-line removal of ocular artifacts. Electroencephalography and Clinical Neurophysiology, 55, $468-484$.

Hill, H., Ott, F., \& Weisbrod, M. (2005). SOA-dependent N400 and P300 semantic priming effects using pseudowords and a delayed lexical decision. International Journal of Psychophysiology, 56(3), 209-221.

Hoff, E., Core, C., Place, S., Rumiche, R., Señor, M., \& Parra, M. (2012). Dual language exposure and early bilingual development. Journal of Child Language, 39(01), $1-27$.

Kiefer, M. (2002). The N400 is modulated by unconsciously perceived masked words: Further evidence for an automatic spreading activation account of N400 priming effects. Cognitive Brain Research, 13(1), 27-39.

Kuipers, J. R., \& Thierry, G. (2013). ERP-pupil size correlations reveal how bilingualism enhances cognitive flexibility. Cortex, 49(10), 2853-2860.

Kuipers, J. R., \& Thierry, G. (2015). Bilingualism and increased attention to speech: Evidence from event-related potentials. Brain and Language, 149, 27-32.

Kutas, M., \& Federmeier, K. D. (2000). Electrophysiology reveals semantic memory use in language comprehension. Trends in Cognitive Sciences, 4(12), 463-470.

Kutas, M., \& Hillyard, S. A. (1980). Reading senseless sentences: Brain potentials reflect semantic incongruity. Science, 207, $203-205$.

Marchman, V. A., Fernald, A., \& Hurtado, N. (2010). How vocabulary size in two languages relates to efficiency in spoken word recognition by young Spanish-English bilinguals. Journal of Child Language, 37, 817-840.

Meyer, D. E., \& Schvaneveldt, R. W. (1971). Facilitation in recognizing pairs of words: Evidence of a dependence between retrieval operations. Journal of Experimental Psychology, 90, 227-234.

Mills, D. L., Coffey-Corina, S. A., \& Neville, H. (1993). Language acquisition and cerebral specialization in 20-month-old infants. Journal of Cognitive Neuroscience, 5(3), 317-334.

Mills, D. L., Coffey-Corina, S., \& Neville, H. J. (1997). Language comprehension and cerebral specialization from 13 to 20 months. Developmental Neuropsychology, 13(3), 397-445.

Neely, J. H. (1977). Semantic priming and retrieval from lexical memory: Roles of inhibitionless spreading activation and limited-capacity attention. Journal of Experimental Psychology: General, 106(3), 226-254.

Neely, J. H. (1991). Semantic priming effects in visual word recognition: A selective review of current findings and theories. In D. Besner, \& G. W. Humphreys (Eds.). Basic progress in reading - visual word recognition (pp. 264-333). Hillsdale, NJ: Erlbaum.

Oller, D., Eilers, R. E., Urbano, R., \& Cobo-Lewis, A. B. (1997). Development of precursors to speech in infants exposed to two languages. Journal of Child Language, 24(02), 407-425.

Pearson, B. Z., Fernandez, S. C., \& Oller, D. K. (1993). Lexical development in bilingual infants and toddlers: Comparison to monolingual norms. Language and Learning, 43(1), 93-120.

Petitto, L. A., Katerelos, M., Levy, B. G., Gauna, K., Tétreault, K., \& Ferraro, V. (2001). Bilingual signed and spoken language acquisition from birth: Implications for the mechanisms underlying early bilingual language acquisition. Journal of Child Language, 28(02), 453-496.

Posner, M. I., \& Snyder, C. R. R. (1975). Attention and cognitive control. In R. L. Solso (Ed.). Information progressing and Cognition: The loyota symposium (pp. 55-85). Hillsdale, NJ: Erlbaum.

Poulin-Dubois, D., Bialystok, E., Blaye, A., Polonia, A., \& Yott, J. (2013). Lexical access and vocabulary development in very young bilinguals. International Journal of Bilingualism, 17(1), 57-70.

Quillian, M. R. (1962). A revised design for an understanding machine. Mechanical Translation, 7, 17-29.

Rämä, P., Sirri, L., \& Serres, J. (2013). Development of lexical-semantic language system: N400 priming effect for spoken words in 18- and 24-month-old children. Brain and Language, 125, 1-10.

Shiffrin, R. M., \& Schneider, W. (1977). Controlled and automatic human information processing: Perceptual learning, automatic attending, \& a general theory. Psychological Review, 84(2), 127-190.

Silva-Pereyra, J., Harmony, T., Villanueva, G., Fernandez, T., Rodriguez, M., Galan, L., et al. (1999). N400 and lexical decisions: Automatic or controlled processing? Clinical Neurophysiology, 110, 813-824.

Singh, L. (2014). One world, two languages: Cross-language semantic priming in bilingual toddlers. Child Development, 85(2), 755-766.

Sirri, L., \& Rämä, P. (2015). Cognitive and neural mechanisms underlying semantic priming during language acquisition. Journal of Neurolinguistics, 35, 1-12.

Sirri, L., \& Rämä, P. (2017). Similar and distinct neural mechanisms underlying semantic priming in the languages of the French-Spanish bilingual children. Bilingualism: Language and Cognition, 1-10.

Styles, S. J., \& Plunkett, K. (2009). How do infants build a semantic system? Language and Cognition, 1(1), 1-24.

Thierry, G., Vihman, M., \& Roberts, M. (2003). Familiar words capture the attention of 11-month-olds in less than 250 ms. NeuroReport, 14(18), 2307-2310.

Torkildsen, J. vK., Sannerud, T., Syversen, G., Thormodsen, R., Simonsen, H. G., Moen, I., et al. (2006). Semantic organization of basic-level words in 20-month-olds: An ERP study. Journal of Neurolinguistics, 19, 431-454.

Torkildsen, J. V. K., Syversen, G., Simonsen, H. G., Moen, I., \& Lindgren, M. (2007). Electrophysiological correlates of auditory semantic priming in 24-month-olds. Brain and Language, 20(4), 332-351.

Willits, J. A., Wojcik, E. H., Seidenberg, M. S., \& Saffran, J. R. (2013). Toddlers activate lexical semantic knowledge in the absence of visual Referents: Evidence from auditory priming. Infancy. The Official Journal of the International Society on Infant Studies, 18(6), 1-23. 